\title{
The Contribution of the Lay Theories Approach to the Study of Groups
}

\author{
Ying-yi Hong \\ Division of Social Science \\ Hong Kong University of Science and Technology \\ Sheri R. Levy \\ Department of Psychology \\ State University of New York at Stony Brook \\ Chi-yue Chiu \\ Department of Psychology \\ University of Hong Kong
}

\begin{abstract}
This special issue highlights the contribution of the lay theories approach to the study of groups. Six articles address the nature, development, and consequences of a variety of lay theories for group perception and behavior. First, these articles illuminate the structural, functional, and dynamic properties of lay theories as well as their scope. Second, the articles address the development of lay theories from diverse theoretical perspectives, including evolutionary, cognitive, developmental, and sociocultural learning. Third, each article documents the consequences of different lay theories for understanding group inferences and judgments. Taken together, these articles propose theoretical extensions of the lay theories approach and suggest practical implications of the lay theories approach for reducing prejudice.
\end{abstract}

The theories people use in their everyday life have been termed lay, implicit, naive, intuitive, common sense, and background beliefs because people are not necessarily aware of their theories or the impact of those theories on their social understanding. The study of the impact of people's lay theories on their social understanding has a long history in personality and social psychology. Pioneers, such as Heider and Kelly, laid the foundation for the study of this topic. Heider's call to study commonsense psychology led to systematic studies of lay people's theories about events and persons in their social world. Heider (1958) proposed that naive perceivers often try to understand their social world in the same way that scientists do. People generate hypotheses based on the naive, lay theories they hold and constantly test their utility. Although many lay theories lack the rigor of scientific theories and can even lead to erroneous predictions, people rely on them to create a

The preparation of this article was partially supported by Grant HKUST6182/98H from the Research Grant Council of the Hong Kong Special Administrative Region, China.

We thank Ian Hansen for his comments on the earlier draft of this article.

Requests for reprints should be sent to Ying-yi Hong, Division of Social Science, Hong Kong University of Science and Technology, Clear Water Bay, Hong Kong. E-mail: sohong@ust.hk stable, meaning system and to understand, interpret, and predict their social world in a relatively efficient way. Similarly, to understand personality patterns, Kelly (1955) focused on examining the personal constructs (theories) people use to understand their relationships with others important to them. From these investigations, he developed a personality theory that focuses on lay theories as the origin of personality patterns.

Elaborating and expanding on this pivotal work, researchers over the past 2 decades have sought to identify different kinds of lay theories that people hold and to spell out their influence on self-perception (e.g., Ross, 1989; Sternberg, 1985) and judgments of others (e.g., Fletcher \& Thomas, 1996; Wright \& Murphy, 1984; see also Social Cognition, Vol. 16, No. 1 [1998], a special issue on naive theories and social judgments). In the most recent wave of this work, researchers have turned to exploring the pivotal role people's background beliefs can have on their perception of and interactions with groups. This research has identified a diverse set of lay theories and applied them to the understanding of groups. Some theories represent lay theories of human sociology (e.g., Hirschfeld, 1996, 1998; Pratto, Sidanius, Stallworth, \& Malle, 1994) or personology (e.g., Dweck, Chiu, \& Hong, 1995a, 1995b; Levy, Stroessner, \& Dweck, 1998; Menon, 
Morris, Chiu, \& Hong, 1999) that set up a cognitive framework for perceiving groups. Other theories represent ideologies that apply to judging groups as well as other social targets (e.g., egalitarianism-humanitarianism; Katz \& Hass, 1988; right-wing authoritarianism; Altemeyer, 1996). Lay theories also may be specific to particular perceived properties of social groups (e.g., McGarty, Haslam, Hutchinson, \& Grace, 1995; Yzerbyt \& Rocher, in press), the relations among the attributes of social groups (e.g., Haslam \& Fiske, 1992; Lickel et al., 2000), specific stereotyped traits associated with groups (e.g., Wittenbrink, Hilton, $\&$ Gist, 1998), or the contextual nature of stereotypes (e.g., Mendoza-Denton, 1999). In each case, such theories have been shown to critically impact cognitions, affect, and intergroup behavior.

The purpose of this special issue is to highlight the contribution of the lay theories approach to the study of groups. Space constraints preclude the possibility of including all the exciting and innovative theorizing and research in this area. The articles in this issue address the nature, development, and consequences of a variety of lay theories for group perception and behavior. First, these articles illuminate the structural, functional, and dynamic properties of lay theories as well as the scope of lay theories. Second, these articles address the development of lay theories from diverse theoretical perspectives, including evolutionary, cognitive, developmental, and sociocultural learning. Finally, these articles show the consequences of different lay theories for understanding and judging groups.

\section{Nature of Lay Theories}

\section{Structural and Functional Properties}

Research on lay theories has been dominated by a functionalist assumption that people are intuitive scientists (Kruglanski, 1990). Motivated primarily by epistemic goals, perceivers have presumably developed naive theories to understand, predict, and control their environment. Thus, in the guiding intuitive scientist metaphor, lay theories, like scientific theories, are products of an inductive-hypothetical-deductive process. For example, drawing on Anderson and Lindsay (1998), Cameron, Alvarez, Ruble, and Fuligni (this issue) propose that lay theories develop with knowledge of one's group memberships and the differences between social groups. According to Cameron et al., "This knowledge leads to the emergence of a specific lay theory - an organized knowledge structure that directs behavior, judgments, and evaluations-about social groups" (p. 117).

In the guiding intuitive scientist metaphor, a lay theory not only possesses the functional properties of a scientific theory but also structural properties. Morris, Menon, and Ames (this issue) maintain that a lay theory is an abstract representation with clear references to ontological distinctions about kinds of things. As such, a theory has a definite domain of application or range of convenience (Kelly, 1955). A theory may contain a set of propositions that are coherently organized into an integrated causal structure or meaning system. Each proposition describes some regular aspects of the phenomena that fall within the theory's range of convenience. Hirschfeld (this issue) shares a similar view. He summarizes the structural properties of lay theories as follows:

\begin{abstract}
Knowledge of persons, nonhuman living kinds, and the natural relations among them coalesces into complex knowledge structures that encompass specific ontological commitments (theory of biological kinds vs. artifacts), a degree of conceptual integration (lay theories must be comprehensive, so that they capture more than simply incidental knowledge), and domain specific causal explanatory frameworks (growth is a biological not physical cause). (p. 107)
\end{abstract}

Like scientific theories, lay theories serve the epistemic function of sense making. Lickel, Hamilton, and Sherman (this issue) maintain that people use lay theories to understand events and to make inferences about social reality. Similarly, Levy, Plaks, Hong, Chiu, and Dweck (this issue) submit that a lay theory provides meaning systems "that impose psychologically meaningful constraints on the infinite variety of interpretations available for a particular stimulus or event" (p. 156).

In sum, a lay theory is defined by a set of structural and functional criteria. As an abstract representation of regular domain-specific relations, a lay theory is different from a concrete episodic representation of the state of affairs. In addition, a lay theory is an organized knowledge structure rather than an isolated belief. Finally, as complex knowledge structures, lay theories set up a framework for imparting meaning and for making inferences about the world around us.

\section{Types of Lay Theories}

Research has identified different types of lay theories. For example, the naive sociology Hirschfeld (this issue) describes refers to some metatheoretical knowledge emerging from an innate module, which permits people to discriminate between different group identities based on the psychological significance of the identities. Other lay theories focus on some basic assumptions about human nature. Levy et al. (this issue) contrast the entity (fixed) view to the incremental (dy- 
namic) view of human nature. For children and adults, static versus dynamic views of human nature foster very different meaning systems about human behavior and therefore very different beliefs about what information is needed to understand and predict group behavior (Dweck, Chiu, \& Hong, 1995a; Levy, Plaks, \& Dweck, 1999). Morris et al. (this issue) discuss the lay theories of agency and distinguish lay theories that emphasize individuals rather than groups (collectives) as primary causal agents of social events. These lay theories of agency assume that individuals or groups possess autonomy, intentionality, and enduring internal characteristics in causing social events. Yzerbyt, Corneille, and Estrada (this issue) also describe an essentialist theory of group, which assumes that social groups possess essential qualities or essences.

Other lay theories have a more specific focus. Lickel et al. (this issue) describe two elements of perceivers' lay theory of groups: intuitive taxonomy of social groups and beliefs about how people within different types of groups regulate social interactions with one another. Specifically, Lickel et al. link the four types of groups they identified in previous work in the United States and Poland (intimacy groups, task groups, social categories, and loose associations) to the four basic relational styles within groups identified by Fiske (1991) in his ethnographic studies (communal sharing, equality matching, market pricing, and authority ranking). They find that the four types of groups are perceived as having some distinct relational styles.

Cameron et al. (this issue) propose that young children possess a preference for familiar groups, which may reflect their naive belief that a familiar group is more preferable than a novel group. These authors also suggest that children with cognitive maturity may develop similarity-based theories of groups, such as "What is similar to me is good and what is different from me is bad" (see also Aboud, 1988). These lay theories therefore relate specifically to the similarity dimension of social groups.

It is important to note that stereotypes are organized knowledge structures rather than isolated beliefs and thus can be considered a type of lay theory (e.g., Wittenbrink et al., 1998). However, stereotypes are theories about specific social groups and thus are more limited in application. In this issue, because of space constraints, we have focused on lay theories that can be applied generally to social groups.

\section{Dynamic Activation and Accessibility}

There are infinite ways to categorize the stimuli and events in our social ecology, and perceivers seem to dissect their social experiences along lines drawn from their lay theories (Murphy \& Medin, 1985). Accord- ingly, lay theories shape different perceptions of the same social experiences. As noted, individuals may believe that human nature is fixed or malleable. They also may believe that the individual or the group is the primary agent that makes things happen. This principle of alternative constructivism underscores the flexibility of cognitive construction and points to the need to explicate the psychological principles that underlie the activation of lay theories.

Chronic accessibility and cultural differences.

A lay theory that has been frequently activated will become chronically accessible (Dweck, Chiu, \& Hong, 1995b; Higgins, 1996). Cross-cultural differences in the relative chronic accessibility of lay theories provide a good illustration of the principle of chronic accessibility. As noted, American culture tends to endorse a conception of agentic individual persons, whereas Chinese culture tends to endorse a conception of agentic collectives (Menon et al., 1999). In their article, Morris et al. (this issue) explicate how culture shapes these two kinds of lay theories of agency. According to them, these differential conceptions of agency are sustained in the two cultures through public representations in texts and institutions. Moreover, the more prominent a given theory of agency is in the public representations of a culture, the more chronic its cognitive accessibility will be for the members of the culture.

Consistent with this view, J. G. Miller (1984) observed that North Americans and Hindus did not differ in their tendencies to make individual or group dispositional attributions when they were young. As they grew older and were more frequently exposed to the public representations of the lay theories in their own cultures, North Americans used an increasing number of individual dispositions to explain social events, whereas Hindus made much more group dispositional attributions for the same events.

Situational activation. Lay theories also can be activated or deactivated in particular situations (for a review, see Levy, 1999). For example, beliefs about whether personal qualities are fixed or malleable can be experimentally manipulated (Chiu, Hong, \& Dweck, 1997; Hong, Chiu, Dweck, Lin, \& Wan, 1999; Levy et al., 1998; see also Levy et al., this issue). In these studies, participants read a fictitious Psychology Today type article that presented strong scientific "evidence" for either an entity or incremental view of personality. Subsequent to reading this article, participants in the entity theory condition made more extreme evaluations of a novel group than did participants in the incremental theory condition. It is also possible to effect theory change by encouraging 
participants to generate persuasive arguments for a particular theory (see Levy et al., this issue).

Perceivers are more likely to apply an essentialist theory of groups when group identities are salient in the situation than when they are not. Rogier and Yzerbyt (1999; see Yzerbyt et al., this issue) reported that when a group of college students engaged in a competitive game, perceivers were more likely to attribute essentialist qualities to a group consisting of students from the same department (high group identity salience condition) than to a group consisting of students from different departments (low group identity salience condition).

If reading a persuasive article and highlighting group identity in an experimental session can increase the likelihood of attributing fixed qualities to a group, sociopolitical changes that highlight intergroup boundaries and group traits should have even stronger effects. This point is consistent with the findings from a case study of the 1997 political transition in Hong Kong. Over the course of the political transition, the conflicts between the Hong Kong group and the Chinese mainland group were made salient. During this period, about half of the Hong Kong college students who originally subscribed to an incremental view shifted to an entity view (Hong, Chiu, Yeung, \& Tong, 1999).

Research on multiculturalism provides another illustration of how lay theories can be situationally induced. Westernized Chinese (e.g., Chinese Americans, Hong Kong Chinese) have been exposed to the theory of collective agency (which is connected to Chinese culture) and that of individual agency (which is connected to U.S. culture). Priming them with icons of Chinese culture can effectively activate their collective agency theory and lead them to prefer group dispositional attributions for the behavior of a group member. Similarly, priming them with icons of American culture can activate their individual agency theory and lead them to favor individual dispositional attributions for the same stimulus behavior (Hong, Morris, Chiu, \& Benet-Martinez, 2000; see also Levy et al., this issue). In short, lay theories are not static. Rather, they are cognitive structures that can be activated by relevant situational cues.

\section{Perceivers' Psychological State}

Some authors in this special issue note that lay theories are resource-saving devices for drawing group inferences. Hirschfeld (this issue) proposes that people develop naive sociology to rank order social groups in terms of their psychological importance to the self. This implicit knowledge can then significantly reduce cognitive demand and increase coherence in interaction. As such, lay theories should dominate group per- ception when the perceivers lack cognitive resources or are unwilling to spend their cognitive resources on effortful information processing. Consistent with this view, research has shown that lay theories tend to dominate group perceptions particularly when perceivers are under cognitive load (Knowles, Morris, Chiu, \& Hong, in press). In addition, when quick causal judgments about social events are called for, people are more likely to rely on the most accessible lay theories of agency in their mind (Chiu, Morris, Hong, \& Menon, 2000). These processes illustrate that the effects of lay theories on group perceptions are dynamically dependent on the perceiver's state of mind.

In sum, to understand how lay theories affect group perceptions, it is necessary to spell out the dynamics by which such theories come to the fore to influence perceptions and judgments.

\section{Development of Lay Theories}

How do lay theories develop? The nativist perspective contends that young children are biologically programmed to acquire lay theories. Hirschfeld (this issue) provides one version of this contention. Drawing on findings in developmental and evolutionary psychology, Hirschfeld proposes that young children have an endogenous lay theory of human kinds. According to him, children, even young ones, are not passive recipients of social information, and their knowledge about the social world is not limited to their immediate, concrete experiences. Using cross-cultural evidence, Hirschfeld shows that the theories children utilize do not necessarily represent an imitation of adults' theories. Rather, children seem capable of deriving their own theories, which could conceivably shape the lay theories that adults in their environment possess. As further evidence supporting an innate cognitive competence, Hirschfeld points out that children do not simply derive their theories based on how perceptually conspicuous groups are; for example, children develop theories about different races and both genders but not about people with different hair color. Hirschfeld describes potential functions served by a "special-purpose endogenous module for identifying and reasoning about human aggregates" (p. 106). He suggests that it may facilitate children's social exchanges and alliances within their complex and diverse social world.

A different view, emphasizing children's cognitive development as a key determinant of the development of lay theories, is proposed by Cameron et al. (this issue). Whereas Hirschfeld (this issue) emphasizes that young children are quite sophisticated lay theorists about human aggregates, Cameron et al. 
caution against the overestimation of the complexity of young children's lay theories about social groups. Cameron et al. argue that young children's lay theories about groups are simplistic, perceptually based, and transitory. These authors' view of children's lay theories derives from social cognitive development theories, socialization theories, and social psychological theories of prejudice and intergroup relations. They propose that children with different levels of cognitive development employ different kinds of lay theories for understanding social groups. Further, they propose that the emergence of prejudice and outgroup hostility requires contextual conditions that emphasize the distinction and differential valuation of social groups. They connect the similarity-difference lay theory to original formulations of social identity theory and to more recent theorizing in the social psychological literature on the utility of separating the similarity and difference components of this lay theory (see Brewer, 1999). Cameron et al. attempt to apply this new formulation and separate the contribution and impact of ingroup favoritism (what is similar to me is good) from outgroup derogation (what is different from me is bad) within the developmental literature on prejudice among children. In doing so, they note that it may be premature to conclude that children hold and apply both similarity and difference lay theories.

Like Cameron et al. (this issue), Morris et al. (this issue) and Levy et al. (this issue) offer a perspective that is rooted in theories of cognitive socialization; however, they emphasize socialization more strongly. Specifically, Morris et al. argue that the developmental perspective, which emphasizes qualitative reorganization of cognitive structures with development, has ignored the cognitive socialization of lay theories. Thus, they propose to supplement the developmental perspective with a theory of cultural learning. Their major argument is that lay theories are carried in external public cultural forms. It is individuals' exposure to the public representations of lay theories in the culture that render a place for these lay theories in the perceiver's mind. Similarly, Levy et al. (this issue) emphasize the malleability of lay theories and highlight the social contexts that could alter or affect the development of lay theories. In their article, they review studies that have shown induction of lay theories through direct manipulation, cultural learning, and experience when facing large-scale sociopolitical changes.

The three perspectives offer a multidimensional view on the development of lay theories. It is entirely possible that, as Hirschfeld (this issue) proposes, human beings are equipped with an innate competence to make distinctions between different social aggregates. At the same time, it is also possible that individuals sample and internalize specific lay theories from the culture, as Morris et al. (this issue) and Levy et al. (this issue) propose. What kind of theory children can comprehend also depends on their cognitive maturity (see Aboud, 1988). Young children may not possess the cognitive readiness to understand conceptually based theories and are therefore dominated by perceptually based theories. Yet, these young children may also possess the metacognitive competence to differentiate and discriminate between different social aggregates, as Hirschfeld posits.

\section{Consequences of Lay Theories}

A common theme in the articles of this special issue is that lay theories play a pivotal role in guiding group perceptions and actions. For example, naive sociology can provide justifications for uneven distribution of resources to different social groups (Hirschfeld, this issue). With research in the United States and East Asia and research concerning familiar and novel groups, Levy et al. (this issue) show that a belief in fixed human character (entity theory) orients people to focus on static aspects of groups (fixed group traits), which then precipitate a perception of high within-group homogeneity and possible avoidance of members of stereotyped groups. In contrast, a belief in malleable human character (incremental theory) orients people to focus on dynamic aspects of groups (e.g., the group's goals and needs or its current environment), which then precipitate a perception of greater within-group variance and between-group commonalties (Hong, Chiu, Yeung, \& Tong, 1999; Levy \& Dweck, 1999; Levy et al., 1998). Morris et al. (this issue) also show that whereas the individual agency theory is associated with the tendency to attribute behavior of a group member to the member's individual dispositions, the group agency theory is connected to the tendency to attribute the same behavior to group dispositions (Menon et al., 1999).

Compared to the influences of more general theories, the influences of group-specific lay theories on group perceptions are more direct, if not more powerful. Lickel et al. (this issue) found that when a group is categorized as a highly integrated group (e.g., intimacy groups or groups with highly interdependent members), perceivers may perceive the group as capable of facilitating or restraining the wrongdoings of group members. In this case, perceivers rate the group as having high collective responsibility for the wrongdoings of group members. Yzerbyt et al. (this issue) also report that an essentialist theory of group may facilitate stereotype formation, and Cameron et al. (this issue) note that 
the belief that what is familiar is preferred could lead to ingroup favoritism.

\section{Theoretical Extensions and Future Directions}

Thus far, we have reviewed the nature, development, and consequences of the lay theories approach for group perception and behavior. Here, we discuss some theoretical extensions and future research directions of the lay theories approach.

\section{Bases of Group Entitativity Perceptions}

A primary focus of recent research on group perception has been on the issue of perceived entitativity, the extent to which aggregates of persons are seen as social entities (Abelson, Dasgupta, Park, \& Banaji, 1998; Brewer \& Harasty, 1996; Campbell, 1958; Hamilton \& Sherman, 1996; Lickel et al., 2000). Perceived entitativity has often been operationalized in terms of perceived group homogeneity; if perceivers attribute the same essentialist qualities to the vast majority of the group, the group is perceived to have high entitativity.

Since Campbell (1958), researchers have sought to identify the perceptual attributes that contribute to the emergence of entitativity. More recently, Dasgupta, Banaji, and Abelson (1999) showed that perceivers tend to attribute hostile intentions and behavioral traits to groups composed of physically similar members (members having the same skin color). In contrast, other researchers have attempted to identify interactional parameters that contribute to entitativity perceptions. Lickel et al. (2000) discovered that groups characterized by frequent group member interaction, common goals, and common outcomes are perceived to have high entitativity.

These findings have led Yzerbyt et al. (this issue) to conclude that there are two clusters of group attributes that contribute to group entitativity. According to Yzerbyt et al., the similarity cluster consists of physical similarity in size, color, proximity, and so on, and the organization cluster consists of interactions and interdependence among group members, goals of the group, and so on. These two clusters of perceptual cues might be linked to two different mental representations of social groups. When group members have similar physical characteristics, they may be perceived as having the same traits (trait-based entitativity). When group members engage in similar activities in a coordinated manner, they may be perceived as having the same goals (goal-based entitativity; see Brewer, Hong,
$\& \mathrm{Li}$, in press). Using the experimental paradigm in Dasgupta et al. (1999), Ip and Chiu (2000) showed that whereas similarity in physical appearance contributes to trait-based entitativity, coherence in group action contributes to group-based entitativity.

Moreover, although group perceptions are linked to the perceptual attributes of the group, perceivers' lay theories may draw their attention to some but not all of these attributes. It is possible that entity theorists (Levy et al., this issue) who seek to diagnose group traits, may rely more on group members' physical characteristics than on their behavioral pattern when they make group entitativity judgments. Thus, when they see a collection of people as a group, they also tend to perceive common traits in the group. By contrast, incremental theorists, who seek to understand group dynamics in terms of group goals, may rely more on group members' behavioral pattern than on their physical appearance when they make group entitativity judgments. When they perceive a collection of people as a group, they are more likely to infer common goals than common traits in the group members. This analysis suggests that like entity theorists, incremental theorists may also attribute essentialist qualities to a group. However, these essentialist qualities are more likely to be goal based than trait based (Chiu, 1994). These contentions can be tested in future research.

\section{Personal and Collective Responsibility}

Lickel et al. (this issue) found that when perceived interdependence is high, perceivers tend to hold the group responsible for the actions of a single group member. Moreover, the relation between perceived interdependence and collective responsibility attribution is largely mediated by two kinds of inferences: (a) the inference that members of the group may have facilitated or encouraged their fellow group member's behavior, and (b) the inference that members of the group have failed to prevent their fellow group member from engaging in the act. Underlying these two kinds of inferences is the belief that the group possesses a collective will and is an active agent that can facilitate or prevent the action of its members.

To the extent the East Asian cultures foster a theory of group agency, East Asians should make stronger collective responsibility attribution than do North Americans. In this connection, Chiu and Hong (1992) found that starting from $746 \mathrm{BC}$, the system of yuan zuo (holding offenders' superordinates, kinsmen, and neighbors responsible for their crime simply because they are related to the offenders) was widely practiced in China. The rationale underlying the practice of yuan $z u o$ was the belief that one's kinsmen and neighbors had the obligation to monitor the offenders' behavior 
and should therefore have been able to prevent the offenders from doing harm. Morris et al. (this issue) also observe that compared to North Americans, Japanese tend to believe that organizations have unified or shared goals. They also tend to believe that the organization (the group) and its members have high levels of social obligation to each other.

Some authors have noted that within the intuitive scientist metaphor, the notion of collective punishment has been dismissed as crude guilt by association (Tetlock, in press). The foregoing analysis suggests that collective responsibility attribution could be seen as a sensible social practice within the lay theory of group agency.

Thus far, we have assumed that perceivers develop lay theories to make sense of reality. Recent research suggests that perceivers may develop lay theories to serve other social needs as well. For example, in the case of collective responsibility attribution, Bell and Tetlock (1989) assumed that perceivers' primary information processing goal is to calibrate culpability judgments based on the dominant norms in the situation. To serve this goal, perceivers develop lay legal theories to guide culpability judgments in specific situations. Bell and Tetlock noted that in U.S. organizations where individual performance is emphasized, blame is handled by identifying the individual "bad apple." In Japanese organizations, by contrast, group values and mutual trust are emphasized. In such organizations, blame is handled by "cleansing" the organization; the head of the organization often becomes the sacrificial lamb, forced by the situation to step down.

More recently, Tetlock (in press) used an intuitive prosecutor metaphor to understand collective blame. The intuitive prosecutor's primary information processing goal is to defend rules and regimes that they endow with legitimacy. Within this framework, collective punishment is seen as a strategy. By linking a group member's action to his or her fellow group members' welfare, the intuitive prosecutor can effectively enforce conventional rules in the society.

These alternative metaphors suggest that aside from making sense of their environment, perceivers have other information processing goals. In addition, each of these goals may be served by a different kind of lay theories (e.g., lay scientific theories, lay legal theories). Depending on which goal is made salient in the situation, a different lay theory will be activated to guide judgment. These ideas echo the notion of constructive alternativism emphasized in the lay theories approach and point to the importance of understanding the meaning construction process in the context of the perceivers' information processing goals.

\section{Lay Theories as a Vehicle for Reducing Prejudice}

In this special issue, researchers from divergent perspectives discuss how perceivers can be led by their lay theories to engage in prejudicial group judgments. For instance, Hirschfeld (this issue) contends that young children are equipped to organize and infer information about human kinds in essentialist terms. Cameron et al. (this issue) discuss how children display prejudice as they develop racial constancy and begin to understand traits as stable dispositions. Levy et al. (this issue) relate a belief in fixed human character to a greater tendency to form static, stereotyped perceptions of groups, and a belief in malleable human character to a greater tendency to form dynamic perceptions of groups. Yzerbyt et al. (this issue) elaborate on how essentialist inferences may lead to the formation of group stereotypes.

One common theme that emerges from these diverse theories is that essentialist inferences (inference of stable, underlying core essences of certain groups) often lead to more rigid, static views of groups, and these views can contribute to prejudice. Yzerbyt et al. (this issue), citing Rothbart and Taylor (1992), emphasize that

Social categories are the consequence of historically situated conventions, needs, and desires. By omitting that their perceived inductive potential only reflects social values and beliefs and is highly variable across cultures and over time, people make a crucial ontological error. (p. 142)

To reduce prejudice, Yzerbyt et al. (this issue) propose to directly attack the beliefs regarding the inherence of group characteristics. Similarly, Levy et al. (this issue) propose to teach or increase the accessibility of the belief in malleable human nature. Future research can test the effectiveness of these proposals in reducing prejudice.

\section{Lay Theories of Stigmatized Group Members}

Because lay theories have been shown to relate to prejudiced processes and practices, research on lay theories, as the previous section illustrates, will likely continue to explore the lay theories of perceivers who perpetuate prejudice (stigmatizers). Relatively little work on lay theories, however, has focused on lay theorists as targets of prejudice. A growing body of work now focuses on how stigmatization influences people's psychological well-being and their interactions with less stigmatized others (see Crocker, Major, \& Steele, 1998; Swim \& Stangor, 1998). 


\section{LAY THEORIES APPROACH}

Stigmatization typically is defined as a concern about how one will be treated and judged based on one's stigma in a given situation (e.g., Goffman, 1963; Jones et al., 1984). Features that typically characterize stigma across contexts are economic disadvantage and membership in a racial minority group (Crocker et al., 1998). Interestingly, like the lay theories approach, this work emphasizes the active role that the stigmatized individuals play in creating meaning systems and devising coping strategies to deal with prejudice and stigma-related stress (e.g., C. T. Miller \& Major, 2000; see also Crocker et al., 1998). In future work, it will be interesting to see the extent to which the lay theories articulated in this special issue apply to understanding how people from stigmatized groups experience different social contexts.

\section{Conclusion}

The contributions to this special issue provide insights to address the nature, development, and consequences of lay theories of social groups. The six articles included in this issue present innovative works from different research areas, ranging from psychological anthropology to developmental psychology, personality psychology, social psychology, and cultural psychology. The contributors come from heterogeneous research traditions. Despite their diverse intellectual background, these contributors have used the same intuitive scientist metaphor to understand the constructive processes of group perceptions. Although the six articles selected for this special issue do not represent the full spectrum of theories of group perception, they nonetheless illustrate the potential utility of the lay theories approach in integrating the diverse theorizing in this research area.

Following the lay theories approach of Heider (1958) and Kelly (1955), researchers have not heralded one or more theories as offering a more correct or true reality than any other theory. Lay theories are functional for the perceiver. At the same time, this new wave of research on lay theories also continues to emphasize the dynamic nature of theories, how they may develop with age, personal experience, and cultural growth and change.

Yet, contemporary research on lay theories goes beyond its early roots. This new line of work is rooted in diverse literatures and integrative perspectives. This not only means that the study of lay theories now casts a wide net in psychological research, but also means that this work can shed new light on important debates and issues in the literature. Contributions are being made to evolutionary accounts of group perception, children's evolving understanding of groups, and the domain specificity of cross-cultural differences. In conclusion, group perceptions and intergroup relations are very complex processes. Although the lay theories approach cannot provide a complete account of these processes, in its early stages it already has contributed significantly to our understanding of these processes.

\section{References}

Abelson, R. P., Dasgupta, N., Park, J., \& Banaji, M. R. (1998). Perceptions of the collective other. Personality and Social Psychology Review, 2, 243-250.

Aboud, F. E. (1988). Children and prejudice. Oxford, England: Basil Blackwell.

Altemeyer, B. (1996). The authoritarian specter. Cambridge, MA: Harvard University Press.

Anderson, C. A., \& Lindsay, J. J. (1998). The development, perseverance, and change of naive theories. Social Cognition, 16, 8-30.

Bell, N. E., \& Tetlock, P. E. (1989). The intuitive politician and the assignment of blame in organizations. In R. A. Ciacalone \& P. Rosenfeld (Eds.), Impression management in the organization (pp. 105-123). Hillsdale, NJ: Lawrence Erlbaum Associates, Inc.

Brewer, M. B. (1999). The psychology of prejudice: Ingroup love or outgroup hate? Journal of Social Issues, 55, 429-444.

Brewer, M. B., \& Harasty, A. S. (1996). Seeing groups as entities: The role of perceiver motivation. In R. M. Sorrentino \& E. T. Higgins (Eds.), Handbook of motivation and cognition (Vol. 3, pp. 347-370). New York: Guilford.

Brewer, M. B., Hong, Y., \& Li, Q. (in press). Dynamic entitivity: Perceiving groups as actors. In V. Yzerbyt, C. M. Judd, \& O. Corneille (Eds.), The psychology of group perception: Contributions to the study of homogeneity, entitativity, and essentialism. Philadelphia: Psychology Press.

Campbell, D. T. (1958). Common fate, similarity, and other indices of the status of aggregates of persons as social entities. Behavioral Sciences, 3, 14-25.

Chiu, C. (1994). Bases of categorization and person cognition. Unpublished doctoral dissertation, Columbia University, New York.

Chiu, C., \& Hong, Y. (1992). The effects of intentionality and validation on individual and collective responsibility attribution among Hong Kong Chinese. Journal of Psychology, 126, 291-300.

Chiu, C., Hong, Y., \& Dweck, C. S. (1997). Lay dispositionism and implicit theories of personality. Journal of Personality and Social Psychology, 73, 19-30.

Chiu, C., Morris, M. W., Hong, Y., \& Menon, T. (2000). Motivated cultural cognition: The impact of implicit theories on dispositional attribution varies as a function of need for closure. Journal of Personality and Social Psychology, 78, 247-259.

Crocker, J., Major, B., \& Steele, C. (1998). Social stigma. In D. T. Gilbert, S. T. Fiske, \& G. Lindzey (Eds.), Handbook of social psychology (Vol. 2, 4th ed., pp. 504-553). New York: McGraw-Hill.

Dasgupta, N., Banaji, M. R., \& Abelson, R. P. (1999). Group entitativity and group perception: Association between physical features and psychological judgment. Journal of Personality and Social Psychology, 77, 991-1003.

Dweck, C. S., Chiu, C., \& Hong, Y. (1995a). Implicit theories and their role in judgments and reactions: A world from two perspectives. Psychological Inquiry, 6, 267-285.

Dweck, C. S., Chiu, C., \& Hong, Y. (1995b). Implicit theories: Elaboration and extension of the model. Psychological Inquiry, 6 , $322-333$. 
Fiske, A. P. (1991). Structures of social life: The four elementary forms of human relations: Communal sharing, authority ranking, equality matching, market pricing. New York: Free Press.

Fletcher, G. J. O., \& Thomas, G. (1996). Close relationship lay theories: Their structure and function. In G. J. O. Fletcher \& J. Fitness (Eds.), Knowledge structures in close relationships: A social psychological approach (pp. 3-24). Mahwah, NJ: Lawrence Erlbaum Associates, Inc.

Goffman, E. (1963). Stigma: Notes on the management of spoiled identity. Englewood Cliffs, NJ: Prentice Hall.

Hamilton, D. L., \& Sherman, S. J. (1996). Perceiving persons and groups. Psychological Review, 103, 336-355.

Haslam, N., \& Fiske, A. P. (1992). Implicit relationship prototypes: Investigating five theories of the cognitive organization of social relationships. Journal of Experimental Social Psychology, $28,441-474$.

Heider, F. (1958). The psychology of interpersonal relations. New York: Wiley.

Higgins, E. T. (1996). Knowledge activation: Accessibility, applicability and salience. In E. T. Higgins \& A. E. Kruglanski (Eds.), Social psychology: Handbook of basic principles (pp. 133-168). New York: Guilford.

Hirschfeld, L. A. (1996). Race in the making: Cognition, culture, and the child's construction of human kinds. Cambridge, MA: MIT Press.

Hirschfeld, L. A. (1998). Natural assumptions: Race, essence, and taxonomies of human kinds. Social Research, 65, 331-349.

Hong, Y., Chiu, C., Dweck, C. S., Lin, D. M., \& Wan, W. (1999). Implicit theories, attributions, and coping: A meaning system approach. Journal of Personality and Social Psychology, 77, 588-599.

Hong, Y., Chiu, C., Yeung, G., \& Tong, Y. (1999). Social comparison during the political transition: Interaction of entity versus incremental beliefs and social identities. International Journal of Intercultural Relations, 23, 257-279.

Hong, Y., Morris, M. W., Chiu, C., \& Benet-Martinez, V. (2000). Multicultural minds: A dynamic constructivist approach to culture and cognition. American Psychologist, 55, 709-720.

Ip, W. M., \& Chiu, C. (2000). Physical versus action similarity as the basis for the emergence of trait- versus goal-based group-entitativity. Manuscript in preparation, University of Hong Kong, Hong Kong.

Jones, E. E., Farina, A., Hastorf, A. H., Markus, H., Miller, D. T., \& Scott, R. A. (1984). Social stigma: The psychology of marked relationships. New York: Freeman.

Katz, I., \& Hass, R. G. (1988). Racial ambivalence and American value conflict: Correlational and priming studies of dual cognitive structures. Journal of Personality and Social Psychology, $55,893-905$.

Kelly, G. A. (1955). The psychology of personal constructs. New York: Norton.

Knowles, E. D., Morris, M. W., Chiu, C., \& Hong, Y. (in press). Culture and cognitive process models of attribution: Evidence for automatic situational correction among Asians. Personality and Social Psychology Bulletin.

Kruglanski, A. W. (1990). Lay epistemic theory in social cognitive psychology. Psychological Inquiry, 1, 181-197.

Levy, S. R. (1999). Reducing prejudice: Lessons from social-cognitive factors underlying perceiver differences in prejudice. Journal of Social Issues, 55, 745-766.

Levy, S. R., \& Dweck, C. S. (1999). The impact of children's static vs. dynamic conceptions of people on stereotype formation. Child Development, 70, 1163-1180.

Levy, S. R., Plaks, J. E., \& Dweck, C. S. (1999). Modes of social thought: Implicit theories and social understanding. In S. Chaiken \& Y. Trope (Eds.), Dual process theories in social psychology (pp. 179-202). New York: Guilford.
Levy, S. R., Stroessner, S. J., \& Dweck, C. S. (1998). Stereotype formation and endorsement: The role of implicit theories. Journal of Personality and Social Psychology, 74, 1421-1436.

Lickel, B., Hamilton, D. L., Wieczorkowska, G., Lewis, A., Sherman, S. J., \& Uhles, A. N. (2000). Varieties of groups and the perception of group entitativity. Journal of Personality and Social Psychology, 78, 223-246.

McGarty, C., Haslam, S. A., Hutchinson, K. J., \& Grace, D. M. (1995). Determinants of perceived consistency: The relationship between group entitativity and the meaningfulness of categories. British Journal of Social Psychology, 34, 237-256.

Mendoza-Denton, R. (1999). Lay contextualism in stereotyping: Situational qualifiers of stereotypes in intuitive theories of dispositions. Dissertation Abstracts International, 60, 0412.

Menon, T., Morris, M. W., Chiu, C., \& Hong, Y. (1999). Culture and the construal of agency: Attribution of individual versus group dispositions. Journal of Personality and Social Psychology, 76, 701-717.

Miller, C. T., \& Major, B. (2000). Coping with stigma and prejudice. In T. F. Heatherton, R. E. Kleck, M. Hebl, \& J. G. Hull (Eds.), The social psychology of stigma (pp. 243-272). New York: Guilford.

Miller, J. G. (1984). Culture and the development of everyday social explanation. Journal of Personality and Social Psychology, 46 961-978.

Murphy, G. L., \& Medin, D. L. (1985). The role of theories in conceptual coherence. Psychological Review, 92, 289-316.

Pratto, F., Sidanius, J., Stallworth, L. M., \& Malle, B. F. (1994). Social dominance orientation: A personality variable predicting social and political attitudes. Journal of Personality and Social Psychology, 67, 741-763.

Rogier, A., \& Yzerbyt, V. Y. (1999). Social attribution: The role of homogeneity in subjective essentialism. Swiss Journal of Psychology, 54, 233-240.

Ross, M. (1989). Relation of implicit theories to the construction of personal histories. Psychological Review, 96, 341-357.

Rothbart, M., \& Taylor, M. (1992). Category labels and social reality: Do we view social categories as natural kinds? In G. Semin \& K. Fiedler (Eds.), Language, interaction and social cognition (pp. 11-36). London: Sage.

Sternberg, R. J. (1985). Implicit theories of intelligence, creativity, and wisdom. Journal of Personality and Social Psychology, 49, $607-627$.

Swim, J. K., \& Stangor, C. (1998). Prejudice: The target's perspective. San Diego, CA: Academic.

Tetlock, P. E. (in press). Deviant functionalist metaphors for judgment and choice: The intuitive politician, theologian, and prosecutor. Psychological Review.

Wegener, D. T., \& Petty, R. E. (Eds.). (1998). Special issue: Naïve theories and social judgment. Social Cognition, 16(1).

Wittenbrink, B., Hilton, J. L., \& Gist, P. L. (1998). In search of similarity: Stereotypes as naive theories in social categorization. Social Cognition, 16, 31-55.

Wright, J. C., \& Murphy, G. L. (1984). The utility of theories in intuitive statistics: The robustness of theory-based judgments. Journal of Experimental Psychology, 113, 301-322.

Yzerbyt, V. Y., \& Rocher, S. (in press). Subjective essentialism and the emergence of stereotypes. In C. McGarty, V. Yzerbyt, \& R. Spears (Eds.), The formation of social stereotypes. Cambridge, England: Cambridge University Press. 